\title{
Research Letter \\ Shared Reproductive State Enhances Female Associations in Dolphins
}

\author{
Luciana M. Möller and Robert G. Harcourt \\ Marine Mammal Research Group, Graduate School of the Environment, Macquarie University, NSW 2109, Australia
}

Correspondence should be addressed to Luciana M. Möller, luciana.moller@gse.mq.edu.au

Received 9 July 2007; Accepted 27 December 2007

Recommended by Daniel I. Rubenstein

Female bottlenose dolphins (genus Tursiops) usually associate at moderate level with other females within social clusters called bands or cliques. It has been suggested that reproductive state may play the predominant role in determining associations within female T. truncatus bands. Here, we test the hypothesis that reproductive state correlates with associations of female Indo-Pacific bottlenose dolphins (T. aduncus). We found that females in similar reproductive state, which included females from late pregnancy to the first year of their calves' life or females from early pregnancy to their calves' newborn period, had higher-association coefficients with each other than they did with females in different reproductive states (females with older calves or without calves). This was observed both within and across social clusters suggesting that reproductive state, at least for pregnant females and those with young calves, plays an important role in determining who to associate with. However, a female's most frequent associate was not always with another in similar reproductive state. We suggest that several factors, including reproductive state, may be of importance in determining associations of female bottlenose dolphins.

Copyright (c) 2008 L. M. Möller and R. G. Harcourt. This is an open access article distributed under the Creative Commons Attribution License, which permits unrestricted use, distribution, and reproduction in any medium, provided the original work is properly cited.

\section{INTRODUCTION}

Group living among female mammals is widespread. The advantages of group living include enhanced access to resources and communal rearing, reduced risk of predation, and protection from male sexual coercion, while costs generally involve competition for critical resources (e.g., $[1,2])$. Therefore, the size and composition of groups usually reflect a balance between benefits and costs of group living [3]. In fission-fusion societies, female social relationships are usually variable (e.g., $[4,5])$, probably reflecting particular socioecological requirements, which may be dependent on the females' developmental stage and condition (e.g., $[6,7]$ ).

Adult female bottlenose dolphins (genus Tursiops) live in complex societies and usually associate at moderate level with other adult females, apart from associating closely with their calves $[5,8,9]$. In Shark Bay, Western Australia, female Tursiops sp. are found within a large social network, where they usually associate with stable subsets of females [9]. Similarly, adult females T. truncatus in Sarasota Bay, Florida, form clusters of frequent associates that share core areas within their home range [5], a pattern also observed for T. aduncus in Port Stephens, southeastern Australia [8].
Wells et al. [5] suggested that while kinship may be of primary importance in the formation of female T. truncatus bands (but see [8]), associations within bands are based on the presence, absence, and imminence of a calf. In a review of dolphin social relationships, Connor et al. [10] proposed that female bottlenose dolphins in similar reproductive state may benefit from associating with each other because they share similar requirements for food and protection. This "similarity principle" has been suggested to underlie social bonds among other female mammals, such as in captive Rhesus monkeys [6]. However, evidence of a correlation between female associations and reproductive state in the wild is still lacking. Here, we investigate whether associations of female Indo-Pacific bottlenose dolphins (T. aduncus) correlate with similar reproductive state.

\section{MATERIALS AND METHODS}

The study was conducted in Port Stephens, southeastern Australia $\left(32^{0} 42^{\prime} \mathrm{S}, 152^{\circ} 06^{\prime} \mathrm{E}\right)$. Bottlenose dolphins can be observed year-round in this area, with about 90 individuals sighted on a regular basis [11]. Based on association patterns 


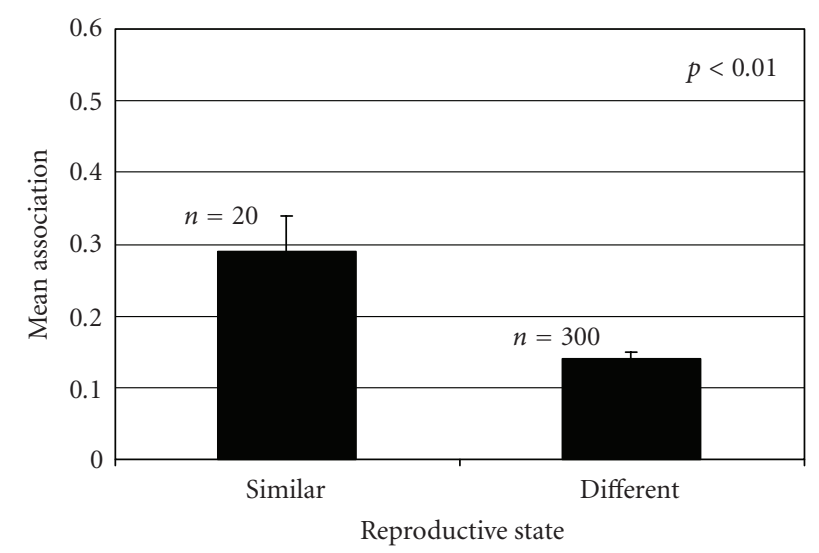

(a)

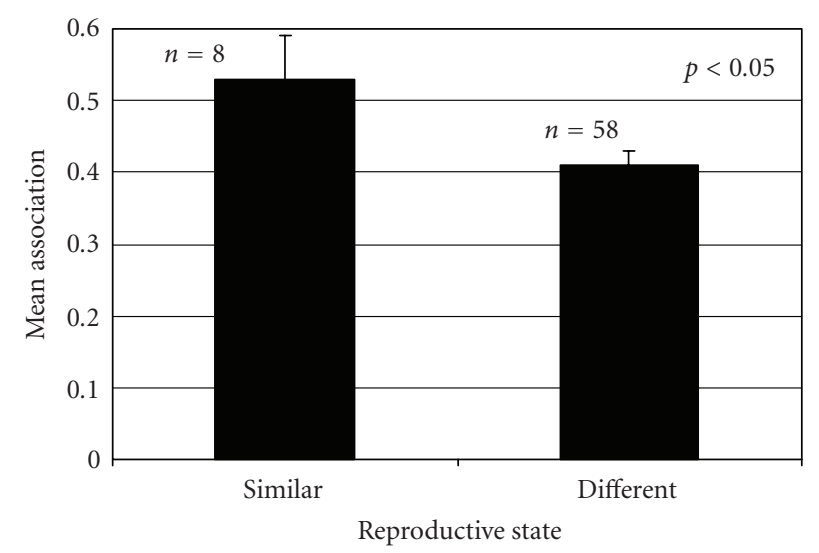

(b)

FIGURE 1: Mean association of female Indo-Pacific bottlenose dolphins in similar and different reproductive states: (a) overall and (b) within social clusters.

and spatial analysis, four main social clusters of females were identified in the area [8].

Between December 1998 and April 2000, 43 boat surveys were conducted in Port Stephens for determining membership of dolphin groups through photo-identification. During this period, 138 individual dolphins were identified. Dolphins were defined as part of the same group if within a $100 \mathrm{~m}$ radius and if the animals were traveling, they were heading in the same direction [8]. Details on surveys and photo-identification procedures can be found in [11]. For analysing association patterns, 158 groups were used out of 218 observed. Groups were selected if at least four times the visually estimated group size was taken in identification photographs, and there was no apparent fusion with animals from other groups while the photographs were being taken [8]. Females were then selected to calculate pairwise associations using the half-weight index (HWI) [12] , if they were sighted in at least 6 groups (the median number of sightings or higher; [8]), using programme SOCPROG 1.2 [13]. The HWI was chosen because it has been used in other dolphin studies based on the premise that individual dolphins are more likely to be identified when apart than when together in the same group (e.g., [9]). Individuals were considered females if they were observed repeatedly with a calf or if they were genetically sexed as such [8]. Only noncalf females were included for analyses. Of all individuals identified during the study period, 65 were of unknown sex, 33 were males, and 40 were females. Since only known females sighted more than 6 times were used for the association analysis, some females (see results) and individuals of unknown sex were excluded.

Pairwise associations between females, which we were able to ascertain that were in similar reproductive state during the study period, were compared with pairwise associations of these females with others that were in different reproductive state. Since the study spans from the beginning of one breeding season to the end of the next breeding season, associations between females in similar reproductive state refer to associations between those females that were in late pregnancy at the beginning of the study and that by the end of the study had a calf of approximately one year of age, as well as associations between those females that were receptive at the beginning of the study and that by end of the study had a newborn calf. Associations between females in different reproductive state refer to associations between those females above with females that had different-aged calves or no calves. Associations between females with possible sameaged calves but of older age classes (among those females that already had calves but not newborns when the study commenced) were not included as similar state because the calves' age could not be determined with certainty. Females without calves were also not included as similar state females because we could not discern with certainty whether these were nulliparous females or females without dependent calves.

Two comparisons were made: one considering associations of females overall (both within and across social clusters) and the other only associations within social clusters (see [8] for information on social clusters). Differences in the mean of female associations were compared using a twosample randomisation test implemented in the programme RT 2.1 [14]. Randomisation tests make no assumption about the distribution or interdependence of the data and therefore are most appropriate for this data set.

\section{RESULTS}

Thirty-five known females were sighted 6 or more times, 28 of which had a closely associated calf (Table 1). Of these females, 10 gave birth during the study period, with five calves born in the first summer and five others in the second summer (Table 1). Overall (i.e., within and across social clusters), females in similar reproductive state were more likely to associate with each other than they were with those in different reproductive states (Figure 1(a)). Within social clusters, there was also a significantly higher mean association between similar-state females compared to different-state females (Figure 1(b)). The most frequent female associate that 
TABLE 1: Social cluster membership (from [8]). Reproductive state and number of sightings of female Indo-Pacific bottlenose dolphins, including an individual's highest association and its closest associate.

\begin{tabular}{|c|c|c|c|c|c|}
\hline Female ID & Social cluster & Reproductive state & Number of sightings & Highest association & Closest associate ID \\
\hline 1 & $\mathrm{~W}$ & $\geq 1 \mathrm{yr}$ & 11 & 0.43 & 36 \\
\hline 3 & $\mathrm{~N}$ & $\geq 1 \mathrm{yr}$ & 17 & 0.33 & 83 \\
\hline 4 & $\mathrm{~N}$ & $\geq 1$ yr, new 2 & 11 & 0.55 & 42 \\
\hline 6 & $\mathrm{~W}$ & New 1 & 15 & 0.38 & 52 \\
\hline 10 & $\mathrm{~W}$ & New 1 & 22 & 0.42 & 11 \\
\hline 11 & $\mathrm{~W}$ & $\geq 1 \mathrm{yr}$ & 16 & 0.55 & 18 \\
\hline 17 & $\mathrm{~N}$ & $\geq 1 \mathrm{yr}$ & 9 & 0.44 & 4 \\
\hline 18 & W & $\geq 1 \mathrm{yr}$ & 20 & 0.74 & 45 \\
\hline 20 & $S$ & $\geq 1 \mathrm{yr}$ & 19 & 0.81 & 54 \\
\hline 21 & S & $\geq 1 \mathrm{yr}$ & 17 & 0.62 & 20 \\
\hline 22 & & $\geq 1 \mathrm{yr}$ & 13 & 0.36 & 20 \\
\hline 29 & S & No calf & 6 & 0.40 & 20 \\
\hline 36 & W & No calf & 13 & 0.48 & 52 \\
\hline 39 & & $\geq 1 \mathrm{yr}$ & 6 & 0.24 & 42 \\
\hline 42 & $\mathrm{~N}$ & No calf, new 2 & 15 & 0.55 & 4 \\
\hline 45 & W & No calf & 12 & 0.74 & 18 \\
\hline 52 & $\mathrm{~W}$ & $\geq 1 \mathrm{yr}$ & 16 & 0.48 & 36 \\
\hline 54 & $\mathrm{~S}$ & $\geq 1 \mathrm{yr}$ & 18 & 0.81 & 20 \\
\hline 61 & K & New 1 & 7 & 0.77 & 66 \\
\hline 62 & $\mathrm{~K}$ & $\geq 1 \mathrm{yr}$ & 6 & 0.67 & 66 \\
\hline 63 & K & No calf, new 2 & 14 & 0.74 & 68 \\
\hline 64 & $\mathrm{~K}$ & $\geq 1$ yr, new 2 & 6 & 0.67 & 61 \\
\hline 65 & $\mathrm{~K}$ & New 1 & 9 & 0.60 & 63 \\
\hline 66 & $\mathrm{~K}$ & New 1 & 6 & 0.77 & 61 \\
\hline 67 & $\mathrm{~K}$ & $\geq 1 \mathrm{yr}$ & 8 & 0.67 & 61 \\
\hline 68 & $\mathrm{~K}$ & No calf, new 2 & 10 & 0.74 & 63 \\
\hline 71 & $\mathrm{~K}$ & $\geq 1 \mathrm{yr}$ & 9 & 0.62 & 64 \\
\hline 73 & $S$ & $\geq 1 \mathrm{yr}$ & 11 & 0.30 & 110 \\
\hline 75 & $\mathrm{~N}$ & $\geq 1 \mathrm{yr}$ & 11 & 0.40 & 4 \\
\hline 79 & $\mathrm{~S}$ & No calf & 8 & 0.29 & 21 \\
\hline 83 & $\mathrm{~N}$ & No calf & 11 & 0.33 & 3 \\
\hline 87 & $\mathrm{~S}$ & No calf & 6 & 0.47 & 54 \\
\hline 110 & S & $\geq 1 \mathrm{yr}$ & 13 & 0.55 & 54 \\
\hline 124 & $\mathrm{~S}$ & $\geq 1 \mathrm{yr}$ & 6 & 0.25 & 110 \\
\hline 132 & K & No calf & 7 & 0.62 & 62 and 66 \\
\hline
\end{tabular}

Reproductive state refers to estimated age or absence of calf at the beginning of the study, and summer of parturition thereafter. New 1 and new 2 refer to newborn in summers 1 and 2, respectively. Females with no cluster membership could not be unambiguously classified as member of any particular main cluster.

was in similar reproductive condition was always within its social cluster. However, its closest associate within the cluster was not always an individual in similar reproductive state (Table 1).

\section{DISCUSSION}

Findings from this study corroborate the hypothesis that similar reproductive state may be an important factor determining female bottlenose dolphin associations [5], at least for pregnant females and those with young calves. Given that bottlenose dolphin females late in gestation and with young calves may be sexually coerced by males [15], these similar reproductive state females may be at considerable risk of injury or separation from their calves. Circumstantial evidence also suggests that males may kill infants (e.g., [16]), and so avoidance of males may be a trait shared by females in similar condition. Sharks also pose a significantly higher risk of predation for mothers and calves, compared to other agesex classes (e.g., [16]). Hence, association with other females in similar reproductive state may provide protection through shared level of risk. In addition, there is evidence from other delphinids that feeding habits may vary with reproductive state. Lactating spotted dolphins (Stenella attenuata) feed preferentially on flying fish, and less so on squid compared to pregnant females [17]. Altered nutritional requirements 
and/or restrictions on foraging ability might, therefore, also drive enhanced associations for pregnant female dolphins and those with young calves. In plain zebras (Equus burchellii), harems containing lactating females are more likely to lead herd movements, possibly to gain preferential access to scarce water [18].

Port Stephens' female dolphins in similar reproductive state had their highest association with females of their own social cluster, but a female's most frequent associate within its cluster was not always with another in similar reproductive condition. This indicates that other factors may also play a role in association preference. These factors may include kinship, age, maternal experience, and social familiarity.

Kinship has been shown to shape associations of many female mammals (e.g., several primates [19]) and has been suggested to be of importance in the formation of female T. truncatus bands [5]. In Port Stephens, both genetic relatedness and maternal kinship have been found to correlate with female associations [8]. Protection from predators and males, and assistance for infant rearing are potential advantages of group living for female bottlenose dolphins $[8,10]$. If this is the case, then related individuals may be preferred for association because they may be more reliable cooperators [2] and because individuals may gain through inclusive fitness effects [20].

In highly social mammals, close social bonds may also form between similar-aged individuals (e.g., baboons, [21]). This, however, may represent a preference of females for associating with paternal half-sisters, especially in species where paternal kin recognition may be present, and reproductive skew is high [21]. The possibility that paternal relatedness and age play a role in female $T$. aduncus associations remains to be tested.

Females may also associate with others depending on their maternal experience. In one population of T. truncatus, the most experienced mothers associated most frequently with other mothers with dependent calves, and primiparous mothers primarily with either nulliparous females, males, or females without dependent calves [22].

Another possibility is that females associate closely with other females with whom they are socially familiar (e.g., [21]). This is particularly likely to occur in bottlenose dolphins, given their long-term associations $[5,10]$ and capability for individual recognition (e.g., [23]). Bottlenose dolphin calves usually stay in close association with their mothers until they are between 3 and 6 years of age, and associate with other calves during this period (e.g., [5]), probably those of their mothers' closest associates. Later, as juveniles, they associate with other juveniles in mixed-sex groups [5]. Therefore, as adults, close female associates may perhaps include the daughters of their mothers' closest associates, with whom they spent part of their infancy, or females with whom they spend their juvenile period. Moreover, even though adult females may not share similar reproductive state at present, they may have done so in the past. Since female inter-birth interval in bottlenose dolphins is variable, and calf mortality is relatively high in the first 3 years of a bottlenose dolphin's life (e.g., [24]), the probability that females will continue to share similar reproductive state in subsequent pregnancies is likely to be low. Thus, while females on average associate more frequently with females in similar reproductive state, probably due to shared requirements, previously close associations may not completely dissipate. Therefore, other close associates may possibly include females with whom they have previously shared similar reproductive state. Further study should consider a multivariate analysis of these potential factors, in addition to reproductive state, in order to evaluate their relative strength on determining associations in these animals.

\section{ACKNOWLEDGMENTS}

Funding was provided by the Graduate School of the Environment, Macquarie University, Australian Geographic and Linnean Society of NSW. The authors thank all those who helped in the field, especially S. Allen and L. Beheregaray. L. Möller was sponsored by CAPES. This project was conducted under approval of the Macquarie University Animal Ethics Committee and Permit from the NSW Department of Environment and Conservation.

\section{REFERENCES}

[1] B. B. Smuts and R. W. Smuts, "Male aggression and sexual coercion of females in nonhuman primates and other mammals: evidence and theoretical implications," Advances in the Study of Behavior, vol. 22, pp. 1-63, 1993.

[2] R. W. Wrangham, "An ecological model of female-bonded primate groups," Behaviour, vol. 75, pp. 262-300, 1980.

[3] H. R. Pulliam and T. Caraco., "Living in groups: is there an optimal group size?" in Behavioural Ecology: An Evolutionary Approach, J. R. Krebs and N. B. Davies, Eds., Blackwell Scientific, Oxford, UK, 1984.

[4] E. Otali and J. S. Gilchrist, "Why chimpanzee (Pan troglodytes schweinfurthii) mothers are less gregarious than nonmothers and males: the infant safety hypothesis," Behavioral Ecology and Sociobiology, vol. 59, no. 4, pp. 561-570, 2006.

[5] R. S. Wells, M. D. Scott, and A. B. Irvine, "The social structure of free-ranging bottlenose dolphins," in Current Mammalogy, vol. 1, pp. 247-305, Plenum Press, New York, NY, USA, 1987.

[6] F. B. M. de Waal and L. M. Luttrell, "The similarity principle underlying social bonding among female rhesus monkeys," Folia Primatologica, vol. 46, no. 4, pp. 215-234, 1986.

[7] J. Mann and B. B. Smuts, "Behavioral development in wild bottlenose dolphin newborns (Tursiops sp.)," Behaviour, vol. 136, no. 5, pp. 529-566, 1999.

[8] L. M. Möller, L. B. Beheregaray, S. J. Allen, and R. G. Harcourt, "Association patterns and kinship in female Indo-Pacific bottlenose dolphins (Tursiops aduncus) of southeastern Australia," Behavioral Ecology and Sociobiology, vol. 61, no. 1, pp. 109117, 2006.

[9] R. A. Smolker, A. F. Richards, R. C. Connor, and J. W. Pepper, "Sex differences in patterns of association among Indian Ocean bottlenose dolphins," Behaviour, vol. 123, no. 1-2, pp. 38-69, 1992.

[10] R. C. Connor, R. S. Wells, J. Mann, and A. J. Read, "The bottlenose dolphin: social relationships in a fission-fusion society," in Cetacean Societies: Field Studies of Dolphins and Whales, J. Mann, R. C. Connor, P. L. Tyack, and H. P. Whitehead, Eds., pp. 91-126, University of Chicago Press, Chicago, Ill, USA, 2000. 
[11] L. M. Möller, S. J. Allen, and R. G Harcourt, "Group characteristics, site fidelity and abundance of bottlenose dolphins (Tursiops aduncus) in Jervis Bay and Port Stephens, southeastern Australia," Australian Mammalogy, vol. 24, pp. 11-21, 2002.

[12] S. J. Cairns and S. J. Schwager, "A comparison of association indices," Animal Behaviour, vol. 35, no. 5, pp. 1454-1469, 1987.

[13] H. P. Whitehead, "SOCPROG 1.2 (for matlab 5.1): programs for analysing social structure," http://is.dal.ca/ hwhitehe/ social.htm, 1999.

[14] B. F. J. Manly, "RT, a program for randomization testing, version 2.1," Centre for Applications of Statistical and Mathematics, University of Otago, 1997.

[15] R. C. Connor, A. F. Richards, R. A. Smolker, and J. Mann, "Patterns of female attractiveness in Indian Ocean bottlenose dolphins," Behaviour, vol. 133, no. 1-2, pp. 37-69, 1996.

[16] P. J. Corkeron, R. J. Morris, and M. M. Bryden, "Interactions between bottlenose dolphins and sharks in Moreton Bay, Queensland," Aquatic Mammals, vol. 13, no. 3, pp. 109-113, 1987.

[17] H. J. Bernard and A. A. Hohn, "Differences in feeding habits between pregnant and lactating spotted dolphins (Stenella attenuata )," Journal of Mammalogy, vol. 70, no. 1, pp. 211-215, 1989.

[18] I. R. Fischhoff, S. R. Sundaresan, J. Cordingley, H. M. Larkin, M. J. Sellier, and D. I. Rubenstein, "Social relationships and reproductive state influence leadership roles in movements of plains zebra, Equus burchellii," Animal Behaviour, vol. 73, no. 5, pp. 825-831, 2007.

[19] J. B. Silk, "Kin selection in primate groups," International Journal of Primatology, vol. 23, no. 4, pp. 849-875, 2002.

[20] W. D. Hamilton, "The genetical evolution of social behavior, I and II," Journal of Theoretical Biology, vol. 7, pp. 1-52, 1964.

[21] K. Smith, S. C. Alberts, and J. Altmann, "Wild female baboons bias their social behaviour towards paternal half-sisters," Proceedings of the Royal Society. Series B, vol. 270, no. 1514, pp. 503-510, 2003.

[22] C. Owen, "A comparison of maternal care by primiparous and multiparous bottlenose dolphins (Tursiops truncatus)—does parenting improve with experience?" MSc thesis, University of California Santa Cruz, Santa Cruz, Calif, USA, 2001.

[23] L. S. Sayigh, P. L. Tyack, R. S. Wells, A. R. Solow, M. D. Scott, and A. Irvine, "Individual recognition in wild bottlenose dolphins: a field test using playback experiments," Animal Behaviour, vol. 57, no. 1, pp. 41-50, 1999.

[24] J. Mann and J. J. Watson-Capps, "Surviving at sea: ecological and behavioural predictors of calf mortality in Indian Ocean bottlenose dolphins, Tursiops sp.," Animal Behaviour, vol. 69, no. 4, pp. 899-909, 2005. 

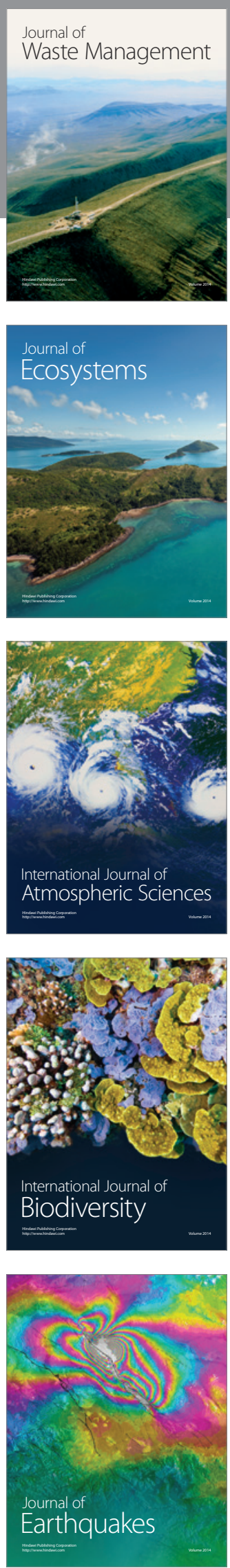
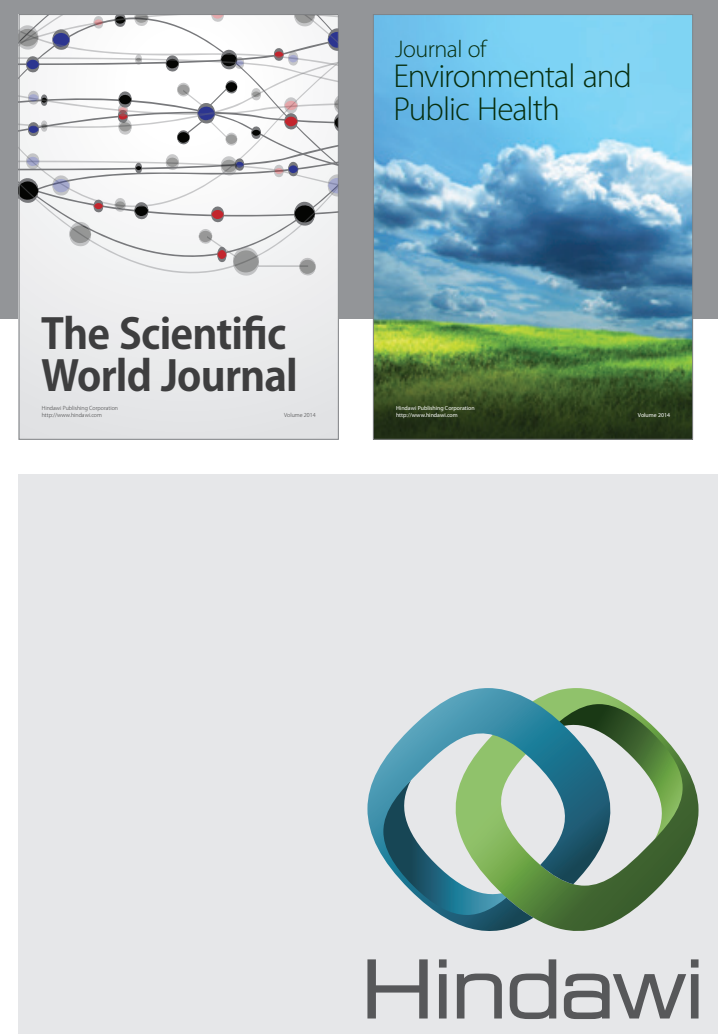

Submit your manuscripts at

http://www.hindawi.com
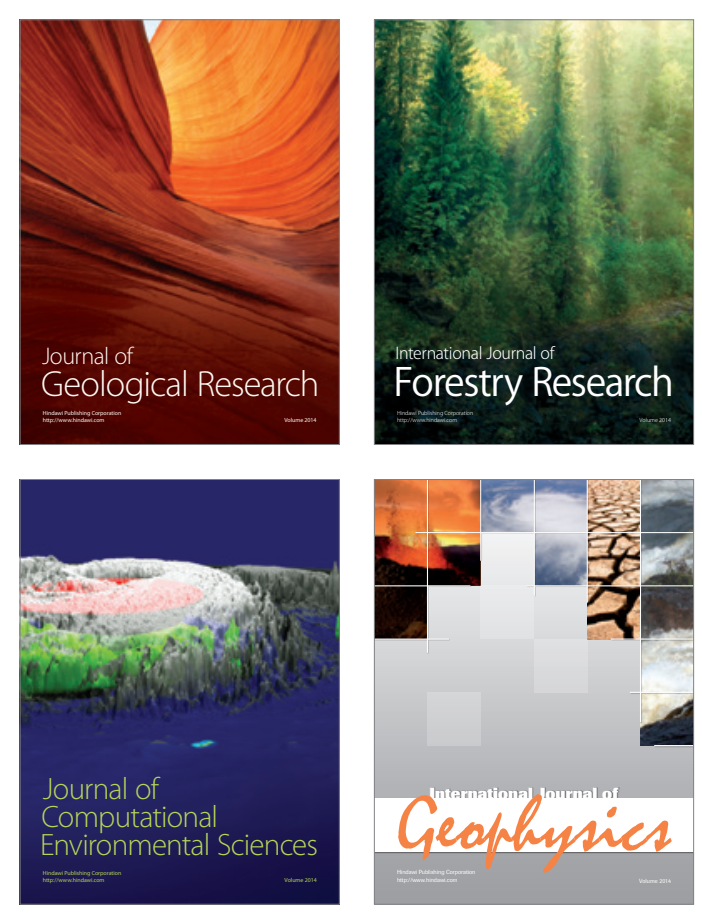
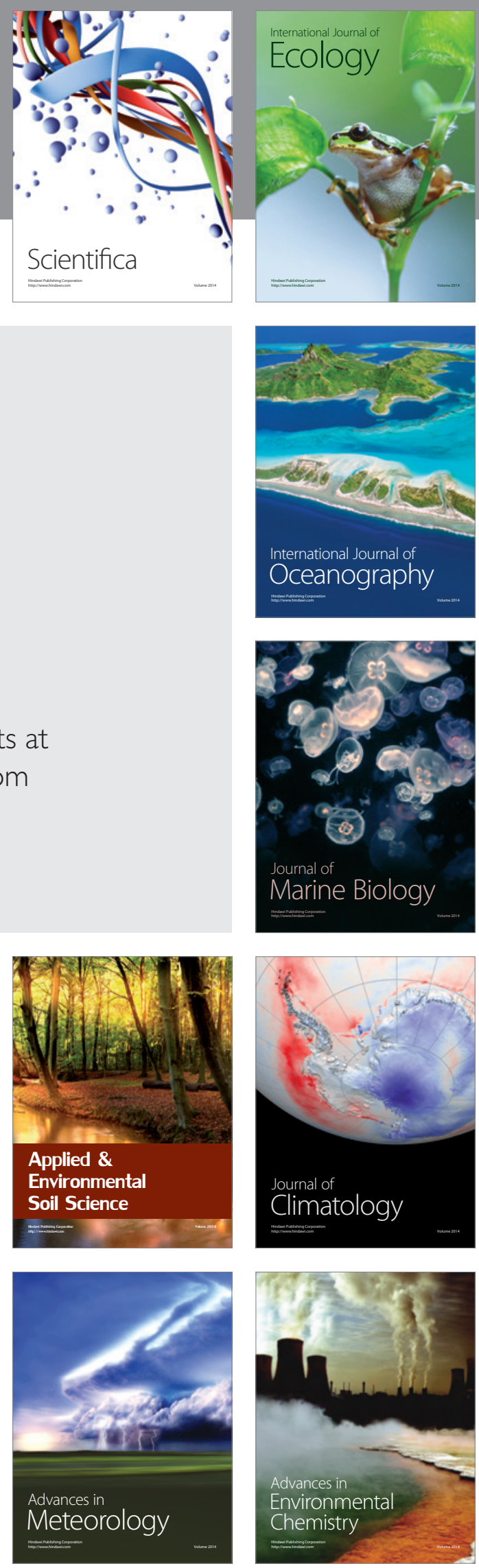